\title{
Transplantation of umbilical cord-derived mesenchymal stem cells as a novel strategy to protect the central nervous system: technical aspects, preclinical studies, and clinical perspectives
}

\author{
Jérémie Dalous ${ }^{1,2}$, Jérome Larghero ${ }^{3,4}$ and Olivier Baud ${ }^{1,2,5}$
}

The prevention of perinatal neurological disabilities remains a major challenge for public health, and no neuroprotective treatment to date has proven clinically useful in reducing the lesions leading to these disabilities. Efforts are, therefore, urgently needed to test other neuroprotective strategies including cell therapies. Although stem cells have raised great hopes as an inexhaustible source of therapeutic products that could be used for neuroprotection and neuroregeneration in disorders affecting the brain and spinal cord, certain sources of stem cells are associated with potential ethical issues. The human umbilical cord (hUC) is a rich source of stem and progenitor cells including mesenchymal stem cells (MSCs) derived either from the cord or from cord blood. hUC MSCs (hUC-MSCs) have several advantages as compared to other types and sources of stem cells. In this review, we will summarize the most recent findings regarding the technical aspects and the preclinical investigation of these promising cells in neuroprotection and neuroregeneration, and their potential use in the developing human brain. However, extensive studies are needed to optimize the administration protocol, safety parameters, and potential preinjection cell manipulations before designing a controlled trial in human neonates.

D ramatic improvements in the perinatal management of premature infants have decreased neonatal mortality and morbidity but have failed to diminish the incidence of white and gray matter damage, the main pathological alterations leading to cerebral palsy. The increased survival of very and extremely preterm infants has progressively led to the emergence of a significant group of infants at high risk for the development of motor, sensory, cognitive, and behavioral deficits, constituting a major challenge for our society (1-3). The prevention of neurological disabilities remains a preoccupying issue in public health, and no neuroprotective treatment to date has proven clinically useful in reducing lesions.

It is hoped that stem cells will provide an inexhaustible source of therapeutic products that will enable neuroprotection and neuroregeneration in disorders affecting the brain and spinal cord. Different sources of stem cells have been described, but some are associated with potential ethical issues. A rich source of stem and progenitor cells that is, however, free of these ethical issues, is the human umbilical cord (hUC, ref. 4).

Stem cells derived from UC or UC blood (UCB) might be suitable for neuroprotection. A few promising experimental studies using human UCB (hUCB)-derived mononuclear cells and hUC-derived mesenchymal stem cells (hUC-MSCs), either from the blood or from Wharton's jelly, have already been undertaken $(5-8)$. Thus, there is increasing interest in studying the potential of UC-derived stem cells for the treatment of brain diseases (9).

This review will summarize the most recent data on the technical aspects and the preclinical use of hUC-MSCs, which are opening up promising perspectives in the neuroprotection and neuroregeneration of the developing human brain.

\section{SOURCES OF MSCS}

Originally identified by Friedenstein in 1976 (10) as a fibroblast-like cellular population in the bone marrow (BM), MSCs are a rare, heterogeneous, stromal population of multipotent nonhematopoietic progenitor cells with the capacity to differentiate into multiple mesenchymal lineages including bone, fat, and cartilage.

As a result of their immunosuppressive capacities in addition to their ability to differentiate toward various lineages $(11,12)$, MSCs have emerged as major candidates in the field of cellbased therapies, particularly in regenerative medicine. Although no specific membrane marker for MSCs has yet been clearly identified, several phenotypical characteristics have facilitated their identification and enrichment. MSCs express several cellsurface antigens such as CD73, CD90, CD105, CD146, and even the recently described CD200 (13), as well as various integrins and adhesion molecules. Because MSCs are a nonhematopoietic cell line, they do not express hematopoietic markers such 
as CD34, CD14, or CD45 (14). Adult human MSCs express intermediate levels of major histocompatibility complex class I molecules on their cell surface but not major histocompatibility complex class II molecules, a property that allows them to be transplanted across major histocompatibility complex barriers. They also synthesize trophic mediators such as growth factors and cytokines involved in the regulation of hematopoiesis, cell signaling, and modulation of the immune response (15).

The BM has long been the major source of MSCs both for basic research programs and for clinical studies in cell therapy. However, BM harvesting is a relatively invasive procedure and performed preferentially in adults, although the frequency, proliferation efficiency, and differentiation capacities of BM-MSCs have been shown to decrease with age (16). Moreover, the use of $\mathrm{BM}$-derived cells is not always acceptable due to the risk of viral contamination. Many groups have, therefore, focused on finding alternative sources of MSCs and have succeeded in isolating them from tissues as varied as adipose tissue, the synovium, the fetal liver, deciduous teeth, amniotic fluid, the UCB, and UC (17-22). Of these, the UCB and UC, in particular Wharton's jelly, are being considered more and more as an alternative source of MSCs. Their many advantages such as accessibility, extraction procedures that are painless for donors, the lack of ethical controversies, and a reduced risk of contamination make them particularly attractive.

\section{ADVANTAGES OF hUC-MSCS AS COMPARED WITH OTHER SOURCES OF STEM CELLS}

The hUC contains many stem cell types, including MSCs $(4,23)$. Cord blood has been demonstrated to be a viable clinical alternative to BM transplantation for 20 years, and allogeneic cord blood banks now run in accordance with international standards of safety, quality control, and graft conservation $(24,25)$.

hUC-derived stem cells have many advantages:

- They are available in potentially large quantities, considering the abundance of umbilical cords with about 135 million births worldwide each year.

- They are easily harvested and manipulated with no harm to the baby or mother, avoiding invasive and uncomfortable BM aspiration procedures.

- There is a limited number of ethical issues to be dealt with, in comparison, for example, with embryonic stem cells (ESCs).

- hUC-MSCs exhibit greater proliferative activity than BM-MSCs $(4,26,27)$.

- They may exhibit low immunogenicity in clinical applications (28).

- They are associated with a lower risk of viral contamination (29).

- They can be collected and used in underrepresented ethnic groups.

hUC-MSCs derived from Wharton's jelly have a relatively high harvest rate as compared with MSCs derived from cord blood or BM $(30,31)$, making it possible to obtain substantial numbers of cells after a few passages without long periods in culture.
Thus, the hUC (and especially Wharton's jelly) appears to be a promising source for cell-based regenerative medicine.

Other stem cells, such as neural stem cells (NSCs) and ESCs, have been shown to be very promising for cell-based therapies $(32,33)$. However, NSCs display decreased neurogenesis and senescence over time in culture (34) and harvesting them from brain tissue is difficult and raises ethical issues. NSCs can also be derived from ESCs, but the potential of ESCs is hampered by ethical questions. Another area of concern when using ESCs and fetal tissue-derived NSCs is their tumorigenicity, documented in animal experiments $(35,36)$ and, sometimes, in clinical trials (37). Furthermore, data regarding the lack of immunogenicity of ESCs are not consistent, and they have been reported to elicit severe immune rejection $(38,39)$.

\section{ISOLATION AND EXPANSION OF hUC-MSCs}

The possibility of using UCB for MSC isolation is still a matter of debate. Some groups have demonstrated the presence of MSCs in UCB, whereas others report that the UCB is not a rich source of MSCs (40-43). The number of MSCs per UCB unit appears to be relatively low, as is their proliferation rate, and MSCs have been isolated from only a small percentage of UCB samples $(44,45)$. In this context, the UC is gaining increasing attention because it contains high amounts of MSCs that have been shown to be isolatable from $100 \%$ of the samples tested by several groups $(27,42,45,46)$. Depending on the derivation protocol used, and the part of the UC from which they were isolated, various types of hUC-MSCs have been reported: UC matrix stem cells, UC perivascular cells, UC stromal cells, Wharton's jelly stem cells, cord-lining membrane MSCs, and UC-lining stem cells (5,20,30,47-49). Even though the MSCs isolated from these various compartments have not yet been compared with each other, they have been shown to resemble BM-MSCs while retaining some specific characteristics: they express mesenchymal markers and, furthermore, constitutively express early embryonic transcription factors such as Nanog, Oct-4, and Sox-2 (50,51); they tend to express lower levels of human leukocyte antigen-DR than their BM counterparts $(20,27)$; their growth behavior, including population doubling time and capacity to be maintained in culture over a long period, has been shown to be better than that of BM-MSCs $(27,45,52)$; the frequency of colony-forming units-fibroblasts in the UC has been demonstrated to be higher than in the BM, ranging from $1: 333$ to $1: 1,609$ (vs. 1:10,000-1:36,000 in the BM) depending on the laboratory and the isolation procedures used $(20,27)$.

UC-derived MSCs also exhibit the functional properties of MSCs from other tissues. Thus, they display immune-privilege properties (52-55), have been shown to be well tolerated in allogeneic transplantation experiments $(56,57)$, and can be differentiated into cells of mesodermal origin such as bone, cartilage, and adipose tissue (58). Moreover, hUC-MSCs cultured in neural induction medium develop neural morphologies and express neural markers such as Nestin, glial fibrillary acidic protein, and NeuN $(5,46,59,60)$, suggesting that they have great potential for cell-based therapies in the context of central nervous system diseases. 
Given the identification of MSC-like populations in various compartments of the human UC, it has rapidly become a priority to develop suitable isolation and expansion protocols for the fast and efficient ex vivo generation of large quantities of cells and to optimize culture protocols that fulfill clinical-grade conditions. Various approaches have been used to isolate hUCMSCs, based mainly on enzymatic treatment or explantation techniques. Strategies for the isolation of hUC-MSCs through enzymatic digestion have mainly been based on the use of collagenase, alone or in combination with other enzymes such as trypsin and hyaluronidase $(20,27,30,46,51,61)$. These protocols have been performed with or without the removal of cord blood vessels, after the dissection of the cord into small pieces or with the total length of the cord without mincing (62). Recently, a new method has been proposed for the isolation of MSCs from Wharton's jelly by the direct delivery of enzymatic solutions into the tissue, similar to the method used for the enzymatic digestion of the pancreas for Langerhans islet isolation (50). To avoid the disadvantages of enzymatic digestion, which has been shown to potentially alter cell proliferation and function, some groups have developed UC explant culture approaches that have been shown to be simple, reproducible, and efficient (63-66). However, considering the heterogeneity of the processes used for cell isolation and expansion, and in view of their use for clinical applications, some groups have tried to develop optimized and standardized methods based on the use of xeno- and serum-free culture media $(52,67,68)$ or by taking advantage of the plastic-adherence properties of MSCs that allow cell expansion without UC dissection or enzymatic digestion (69). In addition, in view of their clinical use in both the autologous and allogeneic settings, hUC-MSCs are likely to be cryopreserved and expanded after an initial thawing step. The capacity of these cells to survive and maintain their differentiation potential after thawing has been addressed by cryopreservation either in the presence of dimethyl sulfoxide by cooling them in a computer-controlled programmable cooler or using dimethyl sulfoxide-free cryoprotectant solutions followed by vitrification $(70,71)$. Regardless of the conditions, cell viability in these studies has been shown to be over $70 \%$. In addition, thawed hUC-MSCs are easily grown, with phenotypes and population doubling times similar to those of fresh cells, and maintain their in vitro osteogenic and adipogenic capabilities $(46,62,70,71)$.

\section{DIFFERENTIATION INTO NEURAL CELLS IN VITRO}

Several groups have reported the in vitro differentiation of hUC-MSCs into neural cells $(5,27,30,59,72-74)$.

In the study by Mitchell et al., porcine Wharton's jelly cells were preinduced with basic fibroblast growth factor overnight. Neuronal differentiation was induced with dimethyl sulfoxide and butylated hydroxyanisole for $5 \mathrm{~h}$ (74). After $3 \mathrm{~d}$, bi- or multipolar neuron-like cells appeared, and stained positively for several neuronal proteins (neuronal class III $\beta$-tubulin, neurofilament $M$, and tyrosine hydroxylase). Glial fibrillary acidic protein-positive cells were also identified in cultures after full induction.
Human UC-MSCs from Wharton's jelly cultured in neuronconditioned medium have also been shown to differentiate into neuron-like cells that express neuron-specific proteins such as NeuN and Neurofilament as well as mRNAs for subunits of the kainate receptor and glutamate decarboxylase. After about $10 \mathrm{~d}$ in culture, $87 \%$ of cells were differentiated and functional, as demonstrated by their generation of an inward current in response to glutamate (73).

In another study, hUC-MSCs cultured in neuron-conditioned medium with sonic hedgehog and fibroblast growth factor 8 were induced to differentiate into dopaminergic neurons in vitro with a success rate of $13 \%$ (ref. 59). Dopamine concentrations in the culture medium were found to be increased after neuronal induction.

Using similar multistep neural induction protocols, $\mathrm{Lu}$ et al. obtained neural differentiation from 9 of $10 \mathrm{UCs}$, and cells with neural morphologies were positive for neuron-specific enolase, an NSC marker (27). Significantly more UC-derived cells were stained than BM-derived cells (61\% vs. 40\%, respectively). Using a classic three-step neural induction method (basic fibroblast growth factor, then $\beta$-mercaptoethanol with neurotrophin-3 (NT-3), and finally, a combination of NT-3, nerve growth factor, and brain-derived neurotrophic factor (BDNF), Ding et al. observed $14 \mathrm{~d}$ later that $60 \%$ of hUC derived cells expressed MAP-2 and 32\% glial fibrillary acidic protein, suggesting that they could differentiate into neurons and astrocytes (72).

It is important to note that in most studies, the in vitro neural differentiation of MSCs was assessed based on the detection of neural cell-related mRNAs and proteins in the treated cells. However, several neural cell-related mRNAs and proteins are also expressed by undifferentiated MSCs (75). Moreover, several studies have shown that in vitro neuronal differentiation protocols using chemical induction medium can produce unexpected and misleading effects, such as changes in cell morphology due to actin cytoskeleton disruption, cell shrinkage, or toxicity (76-79) and the transient upregulation of neural markers without the induction of neural differentiation (80). These reports indicate the need for a more cautious evaluation of MSC differentiation that distinguishes between molecular signaling and lineage commitment steps to reliably assess the ability of MSCs to differentiate into neural cells.

\section{MANIPULATION OF hUC-MSCs: CELL TRACKING, ENGINEERED STEM CELLS}

Human UC-MSCs are extremely valuable candidates for medical applications in various diseases. However, even though they possess a wide range of properties of great interest, MSC-based therapies still face certain hurdles such as low survival after injection, lack of homing to the lesion site and reduced differentiation potential in vivo. In order to circumvent some of these disadvantages and to improve the therapeutic efficacy of MSCs, it has been proposed that the cells be genetically modified to carry therapeutic genes, enhance their migratory properties, or locally deliver biological 
agents $(81,82)$. This has been achieved using viral and nonviral methods, mainly with MSCs isolated from adult tissues. Significant transfection efficiency has also been obtained with MSCs isolated from human UCB and Wharton's jelly $(83-85)$. The combination of properties of MSCs makes them of particular interest for cell-based therapies in central nervous system injury and disease.

Several techniques are available to track hUC-MSCs or to enhance their beneficial effects in cell therapy experiments. For example, to track grafted cells in a transplantation experiment, hUC-MSCs were transfected with the green fluorescent protein (GFP) reporter gene, and GFP-expressing cells sorted using fluorescence-assisted cell sorting (85). Later, the same authors used recombinant adenoviruses containing the NT-3 gene to genetically modify the GFP-hUC-MSCs and make them overexpress NT-3. The resulting cells were transplanted into a rat model of spinal cord injury, and displayed enhanced survival and therapeutic effects (better functional recovery, increased volume of spared myelination, and reduction of cystic cavity) as compared with unengineered hUCMSCs. In another study, Kermani et al. electroporated hUCMSCs to obtain a stable cell line that continuously expressed two transgenes: one coding for GFP and the other for a therapeutic gene, $B D N F$. The authors suggest that genetically manipulated hUCB-MSCs could be used in cell-based gene therapy (86). Ryu et al. recently carried out similar experiments in a mouse model of intracranial glioma (87), using two fundamental features of hUC-MSCs: (i) their property of migrating toward glioma cells, which makes them good vehicles for the delivery of biological agents, and (ii) their ability to secrete therapeutic gene products after adenoviral transduction, enabling the local production of therapeutic agents within tumors. In vivo, these engineered hUC-MSCs significantly inhibited tumor growth and prolonged the survival of glioma-bearing mice.

Viral transduction methods, however, are associated with safety concerns that may be of critical importance when considering clinical applications. Electroporation techniques may thus be preferable. Electroporation has been used to introduce complementary DNA and mRNA constructs into hUC-MSCs, with a transfection efficiency of $31 \%$ and $90 \%$, respectively (88). Recently, a microporation technique based on the electroporation technique has been developed, and is reported to be very efficient and to induce minimal damage when used with MSCs from cord blood. This transfection technique does not affect their proliferative or migratory activity or their ability to differentiate (83).

It is important to note that care should be taken to identify the donor origin of cells in transplantation experiments. Bromodeoxyuridine, bis-benzimide, and GFP are often used to track transplanted cells in vivo. However, the in vivo transfer of such intracellular labels from locally implanted MSCs to resident macrophages and even neurons and astrocytes has already been demonstrated (89-91). Therefore, different techniques should be used to validate the donor origin of labeled cells; in particular, the use of an independent histological marker is advised.
EFFECT OF hUC-MSCS IN ADULT PRECLINICAL MODELS OF NEUROLOGICAL DISORDERS

Most preclinical studies evaluating the neuroprotective effect of hUC-MSCs have been performed in adult animals. Various models of injury to the central nervous system have been used and numerous transplantation protocols using different doses of hUC-MSCs, delays between insult and transplantation, and various administration routes have been assessed.

In an adult rat model of stroke, Koh et al. intracranially injected undifferentiated hUC-MSCs $2 \mathrm{wk}$ after middle cerebral artery occlusion and observed behavioral improvements as early as 1 wk after cell transplantation (92). Of note, the simultaneous injection of a BDNF-neutralizing antibody partially blocked this neurobehavioral amelioration, suggesting that the key player in this neuroprotective effect was BDNF rather than the integration of transplanted cells into host cell networks. Similarly, Ding et al. showed functional improvements and the stimulation of angiogenesis after hUC-MSC transplantation in stroke-injured adult rats (72). In this study, the beneficial effect of hUC-MSCs appears to have been mediated by $\beta 1$-integrin activation. Therefore, central nervous system repair may be promoted by the capacity of stem cells to find the best pathway for survival and interaction with various cell types in the in vivo microenvironment (93). This interaction seems to be very dependent on integrins, proteins that act via inside-out and outside-in signaling to control several cell functions such as survival, adhesion, migration, and differentiation. The varied integrin expression profiles displayed by stem cells from different sources and the importance of integrin-mediated signaling and adhesion during development pinpoint the need to decipher the signaling mechanisms involved (94).

Human UC-derived cells also induced functional improvements in a rat model of stroke when more than $3 \times 10^{6}$ cells were injected intravenously and up to $30 \mathrm{~d}$ after stroke (8). Using this protocol, enhanced synaptogenesis and vascular density, reduced apoptosis in the ischemic boundary zone, and increased proliferation of progenitor cells in the subventricular zone were observed. Most of the transplanted cells died, and there was no significant reduction in infarct volume, regardless of the dose or timing of administration. The beneficial functional impact of stem cell therapy without a reduction in infarct volume has already been observed (72).

Other authors have reported both functional improvements and lesion size reduction in a model of hemorrhagic stroke (95). These beneficial effects were associated with anti-inflammatory effects and decreased neuronal death probably due to the paracrine actions of MSCs.

The effects of hUC-MSCs have also been assessed in animal models of spinal cord injury. Yang et al. reported that the transplantation of $5 \times 10^{5} \mathrm{hUC}-\mathrm{MSC}$ at the lesion site after complete transection of the rat spinal cord promoted significant recovery of locomotion, stimulated the regrowth of injured corticospinal fibers, and increased the number of neurofilament-positive axons around the lesion site (6). Of note, these neuroprotective effects were associated with immunomodulation (a decrease in the microglial and astrocytic responses) and with increased 
levels of human growth factors such as basic fibroblast growth factor and NT-3. Hu et al. obtained similar results, and showed, using an antibody against human nuclei to identify transplanted cells, that large numbers of cells survived for at least $8 \mathrm{wk}$ but remained undifferentiated in the host spinal cord (96). They also observed higher expression levels of glial-derived neurotrophic factor and NT-3 in animals that had received hUCMSCs 3 wk earlier.

Neurodegenerative diseases may also greatly benefit from stem cell-based therapies. To test the therapeutic value of hUC-MSCs, undifferentiated cells were transplanted into the striatum of hemiparkinsonian rats $4 \mathrm{wk}$ after the depletion/ lesioning of dopaminergic neurons (5). Histological and behavioral improvements were reported $12 \mathrm{wk}$ after transplantation, even though all injected cells had disappeared by this time. Xiong et al. engineered hUC-MSCs to make them express GFP and vascular endothelial growth factor. They injected these cells into the rotenone-lesioned striatum of hemiparkinsonian rats, and observed an improvement in apomorphine-induced rotational behavior (97). It should be noted that despite the absence of immunosuppression, no immunological rejection was observed and many transplanted cells survived up to $12 \mathrm{wk}$ after transplantation. The authors suggest that secretion of vascular endothelial growth factor by stem cells could play a role in the observed neuroprotective effects.

\section{POTENTIAL SHORTCOMINGS OF THE USE OF hUC-MSCS}

As hUC-MSCs are considered nonimmunogenic and have immunomodulatory effects, immunosuppression does not appear to be needed when these cells are xenotransplanted. Several reports have demonstrated neuroprotection after experimental hUC-MSC xenotransplantation with or without immunosuppressive treatment, and there is no consensus as to the need for immunosuppression for optimal neuroprotection. Some studies have shown the survival of numerous transplanted cells for periods as long as $4 \mathrm{mo}$, even though no immunosuppression was used $(6,59,97)$. Contrarily, in similar animal models, few transplanted cells could be identified a few weeks after transplantation in immunosuppressed animals (98). Further studies are therefore required to clarify whether immunosuppression is a help or a hindrance in obtaining the most beneficial outcomes in xenotransplantation experiments. This issue appears even more controversial when one considers that rat BM-MSCs when transplanted into the normal adult rat brain elicit a severe inflammatory response, leading to graft rejection by $2 \mathrm{wk}(90,99)$. In addition, human BM-MSCs can induce or inhibit the proliferative response of allogeneic lymphocytes in vitro, depending on the number of MSCs present (100).

The tumorigenicity of transplanted cells is seldom analyzed in preclinical experiments. However, the safety of hUC-MSC transplantation needs to be carefully assessed before clinical applications can be considered. To our knowledge, in studies that examined tumorigenesis in vivo after hUC-MSC transplantation, no tumor formation was reported $(5,97)$.
The protocol for obtaining the most effective neuroprotection remains to be determined in preclinical studies. For example, the time window after injury, the dose of cells transplanted, cell pretreatment before injection, the route of administration, and many other parameters have to be studied in detail before one can envisage well-defined clinical applications. Moreover, the mechanisms associated with neuroprotection and neuroregeneration also need to be better understood.

\section{EFFECT OF hUC-MSCS IN ANIMAL MODELS OF PERINATAL BRAIN INJURY}

A few preclinical studies have analyzed the effects of the transplantation of hUC-MSCs in the developing brain. Lim et al. transplanted BDNF-expressing hUCB-MSCs into the lateral ventricle of healthy mouse pups on first postnatal day (101). These genetically modified hUCB-MSCs were found to be able to survive, migrate, and differentiate into periventricular astrocytes and olfactory bulb neurons, and performed better than non-engineered hUCB-MSCs under the same conditions. In neonatal rats with a hypoxic-ischemic brain injury, Xia et al. reported significant functional improvement after the intracerebral (parenchymal) injection of $10^{5}$ hUCBMSCs (102). Finally, hUCB-MSCs were transplanted into the hippocampus of mice with Niemann-Pick disease type C1 during the early asymptomatic phase (103). hUCB-MSC transplantation induced better motor function and improved brain cholesterol metabolism. It also prevented Purkinje cell loss via antiapoptotic and anti-inflammatory mechanisms. In addition, the injection of hUCB-MSCs increased the number of doublecortin-positive cells in the dentate gyrus, associated with an upregulation in the activation of the PI3K/Akt and Jak2/STAT3 pathways (103).

Many mechanisms leading to neuroprotection or neuroregeneration have been described in preclinical experiments using stem cell therapy. Transplanted stem cells may

- Reduce neural cell death,

- Have immunomodulatory effects by reducing/increasing inflammation or inducing anti-/proinflammatory cytokine transcription,

- Stimulate endogenous repair mechanisms by inducing the recruitment, proliferation, and differentiation of host cells, leading to angiogenesis and neurogenesis, for example, via growth and neurotrophic factor secretion, and

- Migrate to injured areas where they may differentiate and replace damaged or dead cells.

\section{PERSPECTIVES}

MSCs are multipotent, nonhematopoietic progenitor cells that are being explored as a promising new treatment for tissue regeneration. hUC-MSCs have been widely investigated in preclinical cell-based therapy studies as an alternative to BM transplantation. Although their immunomodulatory properties are not yet completely understood, their low immunogenic 
Table 1. Current pediatric and adult trials using hUC-MSCs for neurological disorders (from clinicaltrials.gov, November 2011)

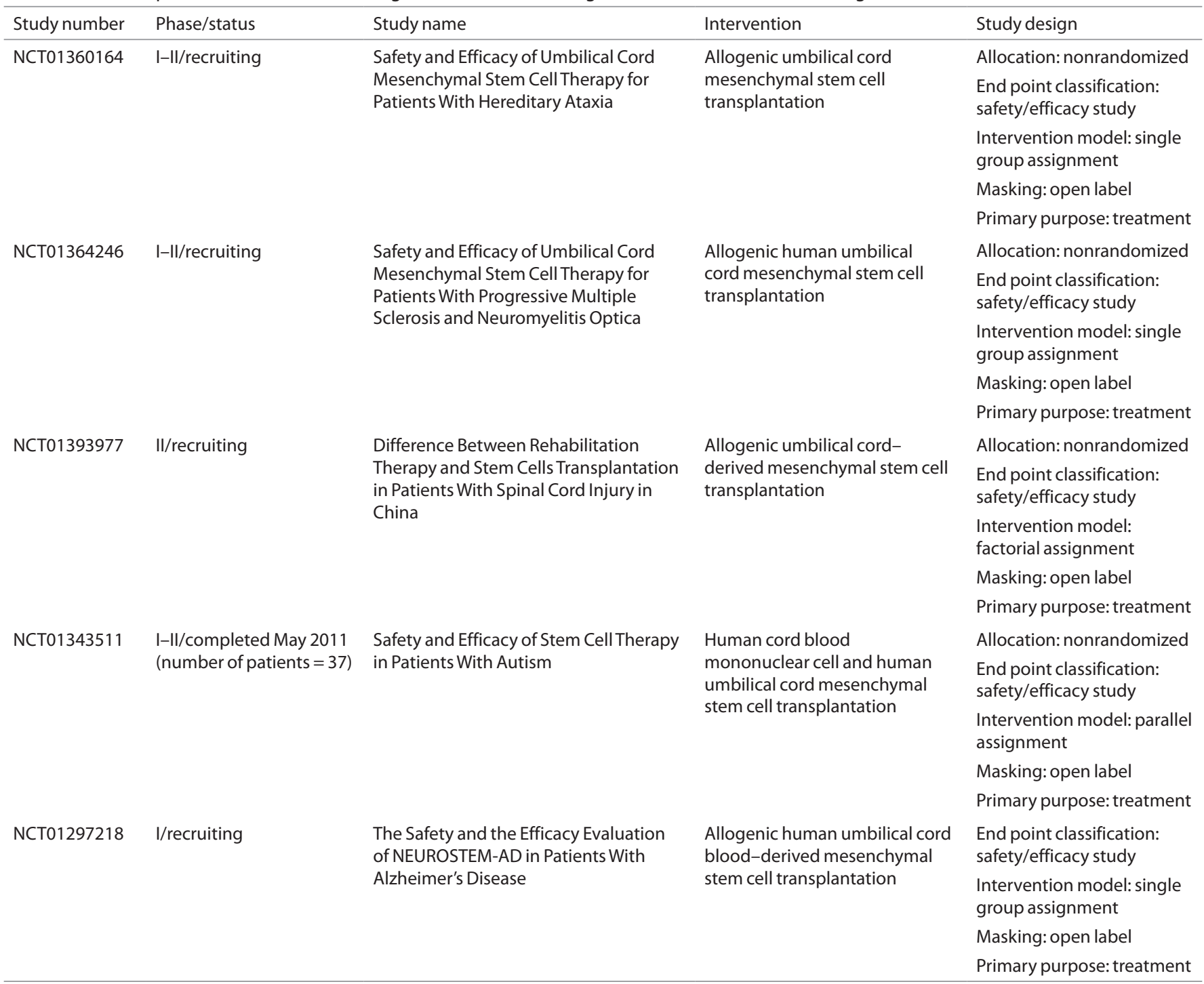

hUC-MSCs, human umbilical cord mesenchymal stem cells.

potential together with their effects on immune responses make them promising therapeutic tools in several human diseases, including autoimmune diseases, endocrine diseases, and neurological disorders. MSCs have already been used in clinical trials as a treatment for acute graft-versus-host disease following allogeneic hematopoietic stem cell transplantation $(104,105)$ and for autoimmune diseases such as systemic sclerosis (106). Table 1 summarizes the current pediatric and adult trials using hUCMSCs for neurological disorders described in clinicaltrials.gov in November 2011. Among these ongoing studies, only one has enrolled infants (suffering from autism) and most of them follow nonrandomized, open-label study designs.

In conclusion, hUC-MSCs could be of great interest in human perinatal neurological disorders, and are good candidates for testing. However, administration protocols, safety parameters and potential preinjection cell manipulations need to be further investigated and optimized before designing controlled trials in human neonates and infants.

\section{REFERENCES}

1. Larroque B, Ancel PY, Marret S, et al.; EPIPAGE Study group. Neurodevelopmental disabilities and special care of 5-year-old children born before 33 weeks of gestation (the EPIPAGE study): a longitudinal cohort study. Lancet 2008;371:813-20.

2. Marlow N, Wolke D, Bracewell MA, Samara M; EPICure Study Group. Neurologic and developmental disability at six years of age after extremely preterm birth. N Engl J Med 2005;352:9-19.

3. Volpe JJ. Neurobiology of periventricular leukomalacia in the premature infant. Pediatr Res 2001;50:553-62.

4. Pappa KI, Anagnou NP. Novel sources of fetal stem cells: where do they fit on the developmental continuum? Regen Med 2009;4:423-33.

5. Weiss ML, Medicetty S, Bledsoe AR, et al. Human umbilical cord matrix stem cells: preliminary characterization and effect of transplantation in a rodent model of Parkinson's disease. Stem Cells 2006;24:781-92.

6. Yang CC, Shih YH, Ko MH, Hsu SY, Cheng H, Fu YS. Transplantation of human umbilical mesenchymal stem cells from Wharton's jelly after complete transection of the rat spinal cord. PLoS ONE 2008;3:e3336.

7. Yu G, Borlongan CV, Stahl CE, et al. Systemic delivery of umbilical cord blood cells for stroke therapy: a review. Restor Neurol Neurosci 2009;27:41-54. 
8. Zhang L, Li Y, Zhang C, Chopp M, Gosiewska A, Hong K. Delayed administration of human umbilical tissue-derived cells improved neurological functional recovery in a rodent model of focal ischemia. Stroke 2011;42:1437-44.

9. Sanberg PR, Willing AE, Garbuzova-Davis S, et al. Umbilical cord bloodderived stem cells and brain repair. Ann N Y Acad Sci 2005;1049:67-83.

10. Friedenstein AJ, Gorskaja JF, Kulagina NN. Fibroblast precursors in normal and irradiated mouse hematopoietic organs. Exp Hematol 1976;4:267-74.

11. Dazzi F, Horwood NJ. Potential of mesenchymal stem cell therapy. Curr Opin Oncol 2007;19:650-5.

12. Pittenger MF, Mackay AM, Beck SC, et al. Multilineage potential of adult human mesenchymal stem cells. Science 1999;284:143-7.

13. Delorme B, Ringe J, Gallay N, et al. Specific plasma membrane protein phenotype of culture-amplified and native human bone marrow mesenchymal stem cells. Blood 2008;111:2631-5.

14. Silva WA Jr, Covas DT, Panepucci RA, et al. The profile of gene expression of human marrow mesenchymal stem cells. Stem Cells 2003;21:661-9.

15. Caplan AI, Dennis JE. Mesenchymal stem cells as trophic mediators. J Cell Biochem 2006;98:1076-84.

16. Rao MS, Mattson MP. Stem cells and aging: expanding the possibilities. Mech Ageing Dev 2001;122:713-34.

17. Campagnoli C, Roberts IA, Kumar S, Bennett PR, Bellantuono I, Fisk NM. Identification of mesenchymal stem/progenitor cells in human first-trimester fetal blood, liver, and bone marrow. Blood 2001;98: 2396-402.

18. De Coppi P, Bartsch G Jr, Siddiqui MM, et al. Isolation of amniotic stem cell lines with potential for therapy. Nat Biotechnol 2007;25:100-6.

19. Romanov YA, Svintsitskaya VA, Smirnov VN. Searching for alternative sources of postnatal human mesenchymal stem cells: candidate MSC-like cells from umbilical cord. Stem Cells 2003;21:105-10.

20. Sarugaser R, Lickorish D, Baksh D, Hosseini MM, Davies JE. Human umbilical cord perivascular (HUCPV) cells: a source of mesenchymal progenitors. Stem Cells 2005;23:220-9.

21. Tsai MS, Lee JL, Chang YJ, Hwang SM. Isolation of human multipotent mesenchymal stem cells from second-trimester amniotic fluid using a novel two-stage culture protocol. Hum Reprod 2004;19:1450-6.

22. Tuan RS, Boland G, Tuli R. Adult mesenchymal stem cells and cell-based tissue engineering. Arthritis Res Ther 2003;5:32-45.

23. Newcomb JD, Willing AE, Sanberg PR. Umbilical cord blood cells. Methods Mol Biol 2009;549:119-36.

24. Broxmeyer HE. Umbilical cord transplantation: epilogue. Semin Hematol 2010;47:97-103.

25. Kurtzberg J. Update on umbilical cord blood transplantation. Curr Opin Pediatr 2009;21:22-9.

26. Baksh D, Yao R, Tuan RS. Comparison of proliferative and multilineage differentiation potential of human mesenchymal stem cells derived from umbilical cord and bone marrow. Stem Cells 2007;25:1384-92.

27. Lu LL, Liu YJ, Yang SG, et al. Isolation and characterization of human umbilical cord mesenchymal stem cells with hematopoiesis-supportive function and other potentials. Haematologica 2006;91:1017-26.

28. Rocha V, Wagner JE Jr, Sobocinski KA, et al. Graft-versus-host disease in children who have received a cord-blood or bone marrow transplant from an HLA-identical sibling. Eurocord and International Bone Marrow Transplant Registry Working Committee on Alternative Donor and Stem Cell Sources. N Engl J Med 2000;342:1846-54.

29. Gluckman E, Rocha V, Chastang C. Peripheral stem cells in bone marrow transplantation. Cord blood stem cell transplantation. Baillieres Best Pract Res Clin Haematol 1999;12:279-92.

30. Karahuseyinoglu S, Cinar O, Kilic E, et al. Biology of stem cells in human umbilical cord stroma: in situ and in vitro surveys. Stem Cells 2007;25:319-31.

31. Manca MF, Zwart I, Beo J, et al. Characterization of mesenchymal stromal cells derived from full-term umbilical cord blood. Cytotherapy 2008; 10:54-68.
32. Bjorklund LM, Sánchez-Pernaute R, Chung S, et al. Embryonic stem cells develop into functional dopaminergic neurons after transplantation in a Parkinson rat model. Proc Natl Acad Sci USA 2002;99:2344-9.

33. TitomanlioL,Bouslama M,LeVercheV,etal.Implantedneurosphere-derived precursors promote recovery after neonatal excitotoxic brain injury. Stem Cells Dev 2011;20:865-79.

34. Wright LS, Prowse KR, Wallace K, Linskens MH, Svendsen CN. Human progenitor cells isolated from the developing cortex undergo decreased neurogenesis and eventual senescence following expansion in vitro. Exp Cell Res 2006;312:2107-20.

35. Brederlau A, Correia AS, Anisimov SV, et al. Transplantation of human embryonic stem cell-derived cells to a rat model of Parkinson's disease: effect of in vitro differentiation on graft survival and teratoma formation. Stem Cells 2006;24:1433-40.

36. Carson CT, Aigner S, Gage FH. Stem cells: the good, bad and barely in control. Nat Med 2006;12:1237-8.

37. Amariglio N, Hirshberg A, Scheithauer BW, et al. Donor-derived brain tumor following neural stem cell transplantation in an ataxia telangiectasia patient. PLoS Med 2009;6:e1000029.

38. Grinnemo KH, Kumagai-Braesch M, Månsson-Broberg A, et al. Human embryonic stem cells are immunogenic in allogeneic and xenogeneic settings. Reprod Biomed Online 2006;13:712-24.

39. Nussbaum J, Minami E, Laflamme MA, et al. Transplantation of undifferentiated murine embryonic stem cells in the heart: teratoma formation and immune response. FASEB J 2007;21:1345-57.

40. Lee OK, Kuo TK, Chen WM, Lee KD, Hsieh SL, Chen TH. Isolation of multipotent mesenchymal stem cells from umbilical cord blood. Blood 2004;103:1669-75.

41. Musina RA, Bekchanova ES, Belyavskii AV, Grinenko TS, Sukhikh GT. Umbilical cord blood mesenchymal stem cells. Bull Exp Biol Med 2007;143:127-31.

42. Secco M, Zucconi E, Vieira NM, et al. Multipotent stem cells from umbilical cord: cord is richer than blood! Stem Cells 2008;26:146-50.

43. Wexler SA, Donaldson C, Denning-Kendall P, Rice C, Bradley B, Hows JM. Adult bone marrow is a rich source of human mesenchymal 'stem' cells but umbilical cord and mobilized adult blood are not. Br J Haematol 2003;121:368-74.

44. Mareschi K, Biasin E, Piacibello W, Aglietta M, Madon E, Fagioli F. Isolation of human mesenchymal stem cells: bone marrow versus umbilical cord blood. Haematologica 2001;86:1099-100

45. Zeddou M, Briquet A, Relic B, et al. The umbilical cord matrix is a better source of mesenchymal stem cells (MSC) than the umbilical cord blood. Cell Biol Int 2010;34:693-701.

46. Fong CY, Subramanian A, Biswas A, et al. Derivation efficiency, cell proliferation, freeze-thaw survival, stem-cell properties and differentiation of human Wharton's jelly stem cells. Reprod Biomed Online 2010;21:391-401.

47. Fong CY, Richards M, Manasi N, Biswas A, Bongso A. Comparative growth behaviour and characterization of stem cells from human Wharton's jelly. Reprod Biomed Online 2007;15:708-18.

48. Gonzalez R, Griparic L, Umana M, et al. An efficient approach to isolation and characterization of pre- and postnatal umbilical cord lining stem cells for clinical applications. Cell Transplant 2010;19:1439-49.

49. Kita K, Gauglitz GG, Phan TT, Herndon DN, Jeschke MG. Isolation and characterization of mesenchymal stem cells from the sub-amniotic human umbilical cord lining membrane. Stem Cells Dev 2010;19: 491-502.

50. Montanucci P, Basta G, Pescara T, Pennoni I, Di Giovanni F, Calafiore R. New simple and rapid method for purification of mesenchymal stem cells from the human umbilical cord Wharton jelly. Tissue Eng Part A 2011;17:2651-61.

51. Tong CK, Vellasamy S, Tan BC, et al. Generation of mesenchymal stem cell from human umbilical cord tissue using a combination enzymatic and mechanical disassociation method. Cell Biol Int 2011;35:221-6.

52. Hatlapatka T, Moretti P, Lavrentieva A, et al. Optimization of culture conditions for the expansion of umbilical cord-derived mesenchymal stem or 
stromal cell-like cells using xeno-free culture conditions. Tissue Eng Part C Methods 2011;17:485-93.

53. Ennis J, Götherström C, Le Blanc K, Davies JE. In vitro immunologic properties of human umbilical cord perivascular cells. Cytotherapy 2008;10:174-81.

54. Weiss ML, Anderson C, Medicetty S, et al. Immune properties of human umbilical cord Wharton's jelly-derived cells. Stem Cells 2008;26:2865-74.

55. Yoo KH, Jang IK, Lee MW, et al. Comparison of immunomodulatory properties of mesenchymal stem cells derived from adult human tissues. Cell Immunol 2009;259:150-6.

56. Azari MF, Mathias L, Ozturk E, Cram DS, Boyd RL, Petratos S. Mesenchymal stem cells for treatment of CNS injury. Curr Neuropharmacol 2010;8:316-23.

57. Bieback K, Brinkmann I. Mesenchymal stromal cells from human perinatal tissues: From biology to cell therapy. World J Stem Cells 2010;2:81-92.

58. Troyer DL, Weiss ML. Wharton's jelly-derived cells are a primitive stromal cell population. Stem Cells 2008;26:591-9.

59. Fu YS, Cheng YC, Lin MY, et al. Conversion of human umbilical cord mesenchymal stem cells in Wharton's jelly to dopaminergic neurons in vitro: potential therapeutic application for Parkinsonism. Stem Cells 2006;24:115-24.

60. Hou L, Cao H, Wang D, et al. Induction of umbilical cord blood mesenchymal stem cells into neuron-like cells in vitro. Int J Hematol 2003;78:256-61.

61. Wang HS, Hung SC, Peng ST, et al. Mesenchymal stem cells in the Wharton's jelly of the human umbilical cord. Stem Cells 2004;22:1330-7.

62. Tsagias N, Koliakos I, Karagiannis V, Eleftheriadou M, Koliakos GG. Isolation of mesenchymal stem cells using the total length of umbilical cord for transplantation purposes. Transfus Med 2011;21:253-61.

63. Ishige I, Nagamura-Inoue T, Honda MJ, et al. Comparison of mesenchymal stem cells derived from arterial, venous, and Wharton's jelly explants of human umbilical cord. Int J Hematol 2009;90:261-9.

64. Majore I, Moretti P, Stahl F, Hass R, Kasper C. Growth and differentiation properties of mesenchymal stromal cell populations derived from whole human umbilical cord. Stem Cell Rev 2011;7:17-31.

65. Petsa A, Gargani S, Felesakis A, Grigoriadis N, Grigoriadis I. Effectiveness of protocol for the isolation of Wharton's Jelly stem cells in large-scale applications. In Vitro Cell Dev Biol Anim 2009;45:573-6.

66. Xu Y, Meng H, Li C, et al. Umbilical cord-derived mesenchymal stem cells isolated by a novel explantation technique can differentiate into functional endothelial cells and promote revascularization. Stem Cells Dev 2010;19:1511-22.

67. Hartmann I, Hollweck T, Haffner S, et al. Umbilical cord tissue-derived mesenchymal stem cells grow best under GMP-compliant culture conditions and maintain their phenotypic and functional properties. J Immunol Methods 2010;363:80-9.

68. Nekanti U, Mohanty L, Venugopal P, Balasubramanian S, Totey S, Ta M. Optimization and scale-up of Wharton's jelly-derived mesenchymal stem cells for clinical applications. Stem Cell Res 2010;5:244-54.

69. De Bruyn C, Najar M, Raicevic G, et al. A rapid, simple, and reproducible method for the isolation of mesenchymal stromal cells from Wharton's jelly without enzymatic treatment. Stem Cells Dev 2011;20:547-57.

70. Liu G, Ye X, Zhu Y, et al. Osteogenic differentiation of GFP-labeled human umbilical cord blood derived mesenchymal stem cells after cryopreservation. Cryobiology 2011;63:125-8.

71. Wang HY, Lun ZR, Lu SS. Cryopreservation of umbilical cord blood-derived mesenchymal stem cells without dimethyl sulfoxide. Cryo Letters 2011;32:81-8.

72. Ding DC, Shyu WC, Chiang MF, et al. Enhancement of neuroplasticity through upregulation of beta1-integrin in human umbilical cord-derived stromal cell implanted stroke model. Neurobiol Dis 2007;27:339-53.

73. Fu YS, Shih YT, Cheng YC, Min MY. Transformation of human umbilical mesenchymal cells into neurons in vitro. J Biomed Sci 2004;11: 652-60.

74. Mitchell KE, Weiss ML, Mitchell BM, et al. Matrix cells from Wharton's jelly form neurons and glia. Stem Cells 2003;21:50-60.
75. Montzka K, Lassonczyk N, Tschöke B, et al. Neural differentiation potential of human bone marrow-derived mesenchymal stromal cells: misleading marker gene expression. BMC Neurosci 2009;10:16.

76. Bertani N, Malatesta P, Volpi G, Sonego P, Perris R. Neurogenic potential of human mesenchymal stem cells revisited: analysis by immunostaining, time-lapse video and microarray. J Cell Sci 2005;118(Pt 17): 3925-36.

77. Choi CB, Cho YK, Prakash KV, et al. Analysis of neuron-like differentiation of human bone marrow mesenchymal stem cells. Biochem Biophys Res Commun 2006;350:138-46.

78. Lu P, Blesch A, Tuszynski MH. Induction of bone marrow stromal cells to neurons: differentiation, transdifferentiation, or artifact? J Neurosci Res 2004;77:174-91.

79. Neuhuber B, Gallo G, Howard L, Kostura L, Mackay A, Fischer I. Reevaluation of in vitro differentiation protocols for bone marrow stromal cells: disruption of actin cytoskeleton induces rapid morphological changes and mimics neuronal phenotype. J Neurosci Res 2004;77:192-204.

80. Rooney GE, Howard L, O’Brien T, Windebank AJ, Barry FP. Elevation of cAMP in mesenchymal stem cells transiently upregulates neural markers rather than inducing neural differentiation. Stem Cells Dev 2009;18:387-98.

81. Hodgkinson CP, Gomez JA, Mirotsou M, Dzau VJ. Genetic engineering of mesenchymal stem cells and its application in human disease therapy. Hum Gene Ther 2010;21:1513-26.

82. Porada CD, Almeida-Porada G. Mesenchymal stem cells as therapeutics and vehicles for gene and drug delivery. Adv Drug Deliv Rev 2010;62:1156-66.

83. Lim JY, Park SH, Jeong CH, et al. Microporation is a valuable transfection method for efficient gene delivery into human umbilical cord bloodderived mesenchymal stem cells. BMC Biotechnol 2010;10:38.

84. Park SA, Ryu CH, Kim SM, et al. CXCR4-transfected human umbilical cord blood-derived mesenchymal stem cells exhibit enhanced migratory capacity toward gliomas. Int J Oncol 2011;38:97-103.

85. Shang AJ, Hong SQ, Xu Q, et al. NT-3-secreting human umbilical cord mesenchymal stromal cell transplantation for the treatment of acute spinal cord injury in rats. Brain Res 2011;1391:102-13.

86. Kermani AJ, Fathi F, Mowla SJ. Characterization and genetic manipulation of human umbilical cord vein mesenchymal stem cells: potential application in cell-based gene therapy. Rejuvenation Res 2008;11:379-86.

87. Ryu CH, Park SH, Park SA, et al. Gene therapy of intracranial glioma using interleukin 12-secreting human umbilical cord blood-derived mesenchymal stem cells. Hum Gene Ther 2011;22:733-43.

88. Friedman R, Betancur M, Boissel L, Tuncer H, Cetrulo C, Klingemann H. Umbilical cord mesenchymal stem cells: adjuvants for human cell transplantation. Biol Blood Marrow Transplant 2007;13:1477-86.

89. Burns TC, Ortiz-González XR, Gutiérrez-Pérez M, et al. Thymidine analogs are transferred from prelabeled donor to host cells in the central nervous system after transplantation: a word of caution. Stem Cells 2006;24:1121-7.

90. Coyne TM, Marcus AJ, Woodbury D, Black IB. Marrow stromal cells transplanted to the adult brain are rejected by an inflammatory response and transfer donor labels to host neurons and glia. Stem Cells 2006;24:2483-92.

91. Pawelczyk E, Jordan EK, Balakumaran A, et al. In vivo transfer of intracellular labels from locally implanted bone marrow stromal cells to resident tissue macrophages. PLoS ONE 2009;4:e6712.

92. Koh SH, Kim KS, Choi MR, et al. Implantation of human umbilical cordderived mesenchymal stem cells as a neuroprotective therapy for ischemic stroke in rats. Brain Res 2008;1229:233-48.

93. Pluchino S, Cusimano M, Bacigaluppi M, Martino G. Remodelling the injured CNS through the establishment of atypical ectopic perivascular neural stem cell niches. Arch Ital Biol 2010;148:173-83.

94. Prowse AB, Chong F, Gray PP, Munro TP. Stem cell integrins: implications for ex-vivo culture and cellular therapies. Stem Cell Res 2011;6:1-12.

95. Liao W, Zhong J, Yu J, et al. Therapeutic benefit of human umbilical cord derived mesenchymal stromal cells in intracerebral hemorrhage 
rat: implications of anti-inflammation and angiogenesis. Cell Physiol Biochem 2009;24:307-16.

96. Hu SL, Luo HS, Li JT, et al. Functional recovery in acute traumatic spinal cord injury after transplantation of human umbilical cord mesenchymal stem cells. Crit Care Med 2010;38:2181-9.

97. Xiong $\mathrm{N}$, Zhang Z, Huang J, et al. VEGF-expressing human umbilical cord mesenchymal stem cells, an improved therapy strategy for Parkinson's disease. Gene Ther 2011;18:394-402.

98. Zhang L, Zhang HT, Hong SQ, Ma X, Jiang XD, Xu RX. Cografted Wharton's jelly cells-derived neurospheres and BDNF promote functional recovery after rat spinal cord transection. Neurochem Res 2009;34:2030-9.

99. Coyne TM, Marcus AJ, Reynolds K, Black IB, Woodbury D. Disparate host response and donor survival after the transplantation of mesenchymal or neuroectodermal cells to the intact rodent brain. Transplantation 2007;84:1507-16.

100. Le Blanc K, Tammik L, Sundberg B, Haynesworth SE, Ringdén O. Mesenchymal stem cells inhibit and stimulate mixed lymphocyte cultures and mitogenic responses independently of the major histocompatibility complex. Scand J Immunol 2003;57:11-20.

101. Lim JY, Park SI, Kim SM, et al. Neural differentiation of brain-derived neurotrophic factor-expressing human umbilical cord blood-derived mesenchymal stem cells in culture via TrkB-mediated ERK and $\beta$-catenin phosphorylation and following transplantation into the developing brain. Cell Transplant 2011, in press.

102. Xia G, Hong X, Chen X, Lan F, Zhang G, Liao L. Intracerebral transplantation of mesenchymal stem cells derived from human umbilical cord blood alleviates hypoxic ischemic brain injury in rat neonates. J Perinat Med 2010;38:215-21.

103. Seo Y, Yang SR, Jee MK, et al. Human umbilical cord blood-derived mesenchymal stem cells protect against neuronal cell death and ameliorate motor deficits in Niemann Pick type C1 mice. Cell Transplant 2011;20:1033-47.

104. Ball LM, Bernardo ME, Roelofs H, et al. Cotransplantation of ex vivo expanded mesenchymal stem cells accelerates lymphocyte recovery and may reduce the risk of graft failure in haploidentical hematopoietic stemcell transplantation. Blood 2007;110:2764-7.

105. Le Blanc K, Frassoni F, Ball L, et al.; Developmental Committee of the European Group for Blood and Marrow Transplantation. Mesenchymal stem cells for treatment of steroid-resistant, severe, acute graft-versushost disease: a phase II study. Lancet 2008;371:1579-86.

106. Christopeit M, Schendel M, Föll J, Müller LP, Keysser G, Behre G. Marked improvement of severe progressive systemic sclerosis after transplantation of mesenchymal stem cells from an allogeneic haploidentical-related donor mediated by ligation of CD137L. Leukemia 2008;22:1062-4. 